\title{
NMR structure and bactericidal activity of KR-12 analog derived from human LL-37 as a potential cosmetic preservative
}

\author{
Hyosuk Yun ${ }^{1}$, Hye Jung Min ${ }^{2^{*}}$ and Chul Won Lee ${ }^{1^{*}}$
}

\begin{abstract}
KR-12 was derived from the human antimicrobial peptide, LL-37. KR-12 maintains the antimicrobial activity of LL-37 and has low toxicity against human cells, thereby showing a high potential for various applications. In this study, the three-dimensional structure of KR-12 analog (KR-12-pa) was determined by solution NMR spectroscopy. The NMR structure of KR-12-pa revealed a nearly perfect amphipathic a-helical structure composed of multiple hydrophobic and positively charged residues. The minimal inhibitory concentration of KR-12-pa for various bacterial and yeast cells suggested that KR-12-pa has a much stronger antimicrobial activity than commercial cosmetic preservatives. In addition, KR-12-pa in cosmetic formulations showed much stronger bactericidal effects than conventional cosmetic preservatives and very low cytotoxicity to mammalian cells. These results suggest that KR-12-pa is applicable as a cosmetic preservative.
\end{abstract}

Keywords: Antimicrobial peptide, Bactericidal, Cosmetic preservatives, LL-37, NMR structure

\section{Introduction}

Cosmetics contain many organic compounds such as glycerin and sorbitol, which can serve as a carbon source for microorganisms, and amino acid derivatives and proteins, which are nitrogen sources and may cause growth of microorganisms and lead to alteration in the contents (Kim 2004). Contaminated cosmetics can cause serious problems such as skin irritation, allergic reactions, phototoxicity, and photoallergy. Therefore, preservatives such as parabens are essentially used for sterilization and preservation of cosmetics; however, cytotoxicity and skin allergy are a cause of concern. In particular, because of problems such as contact dermatitis caused by chemical preservatives and risk of endocrine disruption due to accumulation, preference for natural cosmetics or organic cosmetics is clearly increasing, and there has been a rapid development in the production of natural

\footnotetext{
*Correspondence: sarock@kwu.ac.kr; cwlee@jnu.ac.kr

${ }^{2}$ Department of Pharmaceutical Cosmetics, Kwangju Women's University, Gwangju 62396, Republic of Korea

'Department of Chemistry, Chonnam National University, Gwangju 61186, Republic of Korea
}

\section{Springer Open}

preservatives using natural ingredients (Ahn et al. 2009; Kwon et al. 2015). However, owing to the disadvantages of natural materials, such as odor, color, narrow antibacterial spectrum, content and stability of the formulation, sustainability of antiseptic power, and high costs of securing raw materials, the compatibility is poor (Hwang and Park 2009). Furthermore, with advances in the field of biotechnology, there has been rapid progress in identifying functional ingredients with new efficacies. However, the development of harmless and effective preservatives remains difficult. Therefore, extensive research is being conducted to develop natural antiseptic materials to replace harmful chemical preservatives (Cho et al. 2015; Kwon et al. 2015; Hwang and Park 2009; Choun et al. 2017).

Cosmetic materials have been developed mainly using synthetic compounds or extracts derived from natural products. Recently, there has been a rapid increase in the production of biocosmetic materials using enzymes or microorganisms, the active ingredients of which are naturally

(c) The Author(s). 2020 Open Access This article is licensed under a Creative Commons Attribution 4.0 International License, which permits use, sharing, adaptation, distribution and reproduction in any medium or format, as long as you give appropriate credit to the original author(s) and the source, provide a link to the Creative Commons licence, and indicate if changes were made. The images or other third party material in this article are included in the article's Creative Commons licence, unless indicated otherwise in a credit line to the material. If material is not included in the article's Creative Commons licence and your intended use is not permitted by statutory regulation or exceeds the permitted use, you will need to obtain permission directly from the copyright holder. To view a copy of this licence, visit http://creativecommons.org/licenses/by/4.0/. 
produced by using biotechnological methods by living organisms (Novak et al. 2014; Vandamme 2001)

Antimicrobial peptides (AMPs) are an important component of the innate immune system and are produced by almost all living organisms, from plants and insects to mammals, including humans. The ability to physically destroy bacterial cell membranes and induce lysis allows AMPs to target bacteria, fungi, and enveloped viruses and renders them a potential alternative to conventional antibiotics (Hoskin and Ramamoorthy 2008; Kang et al. 2019; Mani et al. 2006; Porcelli et al. 2013). LL-37 is a natural antimicrobial peptide expressed in the human body. Human cathelicidin LL-37 is a long peptide with 37 amino acids. It is structurally cationic and is an amphiphilic $\alpha$-helical AMP (Johansson et al. 1998). It is known to exhibit direct antimicrobial activity by binding and neutralizing LPS. Therefore, LL-37 has been recognized as an effective treatment for gram-negative bacterial infections and inflammatory diseases. KR-12 (KRIVQRIKDFLR- $\mathrm{NH}_{2}$ ), a peptide from LL-37, is the shortest derivative with antimicrobial activity. KR-12 retains the amphipathic helical conformation of LL-37 and contains five positively charged residues. In particular, LL-37 is known to display hemolytic activity against human red blood cells, but KR-12 does not induce hemolysis. Jacob et al. reported that a variety of KR-12 analogs show higher inhibition of lipopolysaccharide (LPS)-stimulated tumor necrosis factor- $\alpha$ production and LPS-binding activity than wild-type KR-12 peptide (Jacob et al. 2013). In particular, a KR-12 analog with a nearly perfect amphipathic $\alpha$-helical structure (hereinafter named KR-12-pa) showed highly effective antimicrobial and anti-inflammatory activities. In this study, we determined the three-dimensional structure of the KR-12-pa using solution 2D nuclear magnetic resonance (NMR) spectroscopy and evaluated its bactericidal activity in a cosmetic formulation. The KR-12-pa folds into a symmetric amphipathic $\alpha$-helical structure in a membrane-like environment. This peptide showed strong antimicrobial activity against various bacteria and fungi and also showed excellent antimicrobial activity even when used in cosmetic preparations. Moreover, it showed low toxicity to mammalian cells. Therefore, KR12-pa shows a potential to be developed as a new stable cosmetic preservative to replace cosmetic preservatives causing side effects.

\section{Materials and methods}

\section{Chemicals and reagents}

9-Fluorenylmethoxycarbonyl (Fmoc) amino acids and amide resin (GL BioChem, China) were used. All reagents including fluorescein isothiocyanate (FITC) and 3-(4,5-dimethylthiazol-2-yl)-2,5-diphenyltetrazolium bromide (MTT) were obtained from Sigma-Aldrich
(USA). All bacterial strains were obtained from the Korean Collection for Type Cultures (KCTC). These strains were stored at $-80{ }^{\circ} \mathrm{C}$ in $20 \%$ (v/v) glycerol until subcultured onto Luria-Bertani (LB) agar plate for further studies.

\section{Peptide synthesis and purification}

The KR-12-pa and melittin peptides were synthesized by solid-phase peptide synthesis (SPPS) using Fmoc chemistry with amide resin and various blocking groups for sidechain protection. The protected peptides were cleaved from the resin with a mixture of trifluoroacetic acid (TFA), thioanisole, phenol, $\mathrm{H}_{2} \mathrm{O}$, and ethanedithiol (EDT) (a volume ratio of 82.5:5:5:5:2.5) for $3 \mathrm{~h}$ at $25^{\circ} \mathrm{C}$. The cleaved crude peptides were washed with cold diethyl ether three times and were lyophilized. The crude KR-12-pa and melittin peptides were purified using reverse-phase high-performance liquid chromatography (RP-HPLC) (Shimadzu, Japan) on a $\mathrm{C}_{18}$ column (Shimpack PREP-ODS) monitored by UV absorbance at 230 $\mathrm{nm}$. The mobile phase components were $0.05 \%$ TFA in water (solvent A) and $0.05 \%$ TFA in acetonitrile (ACN) (solvent B). The purified peptides were confirmed by LC-MS (API2000, AB SIEX, USA). The purity of the synthesized KR-12 peptides was confirmed by analytical RP-HPLC (all peptides above 95\% pure).

\section{CD spectroscopy}

The secondary structure of KR-12-pa in a $50-\mathrm{mM}$ sodium phosphate buffer ( $\mathrm{pH} 6.5$ ) or $50 \%$ TFE solution was characterized by circular dichroism (CD) spectroscopy. CD spectra of the peptide were recorded at $25^{\circ} \mathrm{C}$ using a Jasco J-810 CD spectrophotometer (Tokyo, Japan). The samples were scanned by using $1-\mathrm{mm}$ path length quartz cells, at a peptide concentration of 100 $\mu \mathrm{M}$. The spectra were averaged over 3 scans.

\section{NMR spectroscopy}

NMR spectra of KR-12-pa were measured using a Bruker 600 spectrometer. The NMR sample for ${ }^{1} \mathrm{H} 2 \mathrm{D}$ NMR experiments was a 2-mM KR-12-pa peptide dissolved in $50 \%$ TFE with a $50-\mathrm{mM}$ sodium phosphate (pH 6.5) containing a 50-mM sodium chloride and $10 \%$ $\mathrm{D}_{2} \mathrm{O}$. 2D double-quantum-filtered correlation spectroscopy (DQF-COSY), total correlation spectroscopy (TOCSY), and nuclear Overhauser Effect Spectroscopy (NOESY) spectra were acquired at $298 \mathrm{~K}$. The TOCSY spectrum of KR-12-pa was recorded using a MLEV-17 pulse scheme with a 70-ms mixing time (Bax and Davis 1985). The NOESY spectrum of KR-12-pa was recorded with a 300-ms mixing time. NMR data of KR-12-ps were processed and analyzed using NMRPipe (Delaglio et al. 1995) and NMRView software (Johnson and Blevins 1994). The resonance assignments of KR-12-pa have 
(a)
$\mathrm{LL}-37$
LLGDFFRKSKEKIGKEFKRIVQRIKDFLRNLVPRTES
$\mathrm{KR}-12-\mathrm{pa}$
KRIVQRIKDFLR
KRIVKRIKKWIR

KR-12

(b)

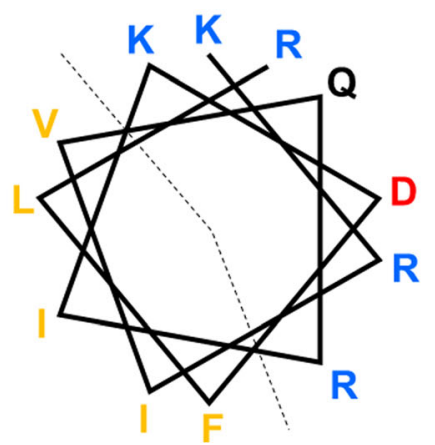

KR-12-pa

(c)

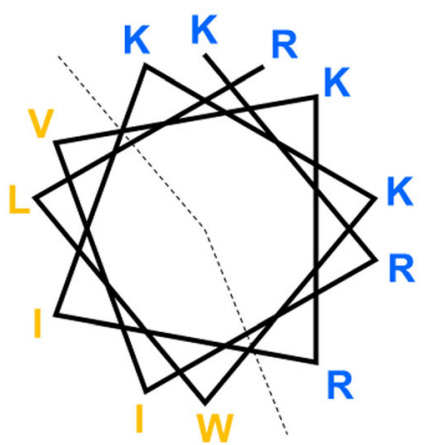

Fig. 1 Primary sequences and helical wheel diagrams of LL-37, KR-12, and KR-12-pa. Positively charged residues are in blue. Negatively charged residues are in red. Hydrophobic residues are in yellow

been deposited to the BioMagResBank database under accession number 36316.

\section{Structure calculation}

The NOE resonance assignments and initial NOE constraints for the KR-12-pa peptide were obtained by CYANA program (Herrmann et al. 2002). The final
NOE constraints were confirmed and refined during the structure calculations. Iterative refinement and editing of the distance constraints based on the NOESY spectra to remove incorrect and ambiguous assignments reduced the number of constraints. The final 20 structures of KR-12-pa with the lowest target function were chosen for analysis and were deposited in the Protein Data Bank

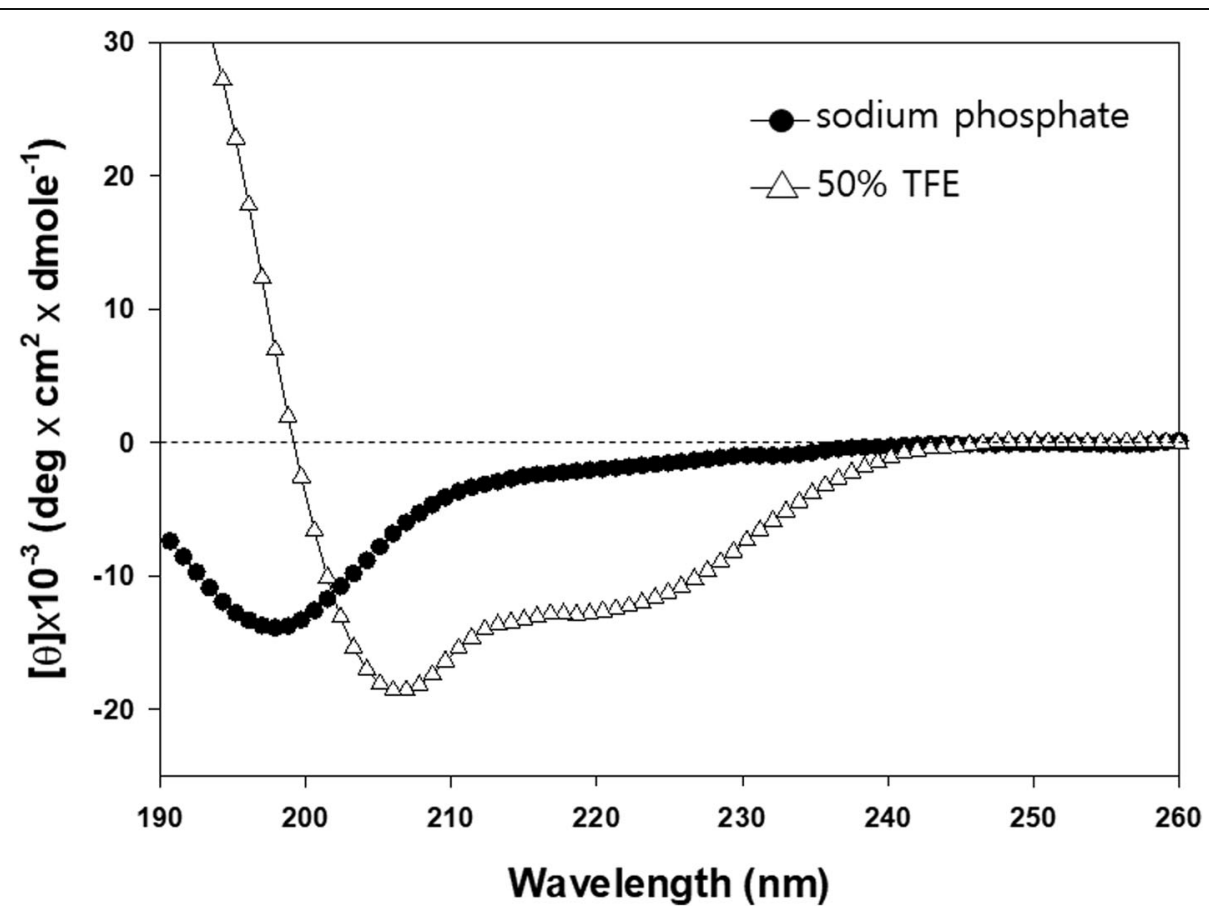

Fig. 2 CD spectra of KR-12-pa in a 50-mM sodium phosphate ( $\mathrm{pH}$ 6.5) (filled circles) and 50\% TFE (open triangles). The mean residue ellipticity was plotted against wavelength. The values from three scans were averaged per sample 
(accession code 6M0Y). All structure images were prepared with MOLMOL program (Koradi et al. 1996).

\section{Determination of minimal inhibitory concentration}

The antimicrobial activities of the KR-12-pa, melittin, methylparaben, and Scutellaria baicalensis extract samples were verified by determining the minimal inhibitory concentration (MIC) in sterile 96-well plates as follows. Aliquots $(100 \mu \mathrm{L})$ of bacterial cell suspension at $4 \times 10^{6}$ $\mathrm{CFU} / \mathrm{mL}$ in $1 \%$ peptone were added to $100 \mu \mathrm{L}$ of the sample solutions (serial 2 -fold dilutions in $1 \%$ peptone). After incubation for $16 \mathrm{~h}$ at $37^{\circ} \mathrm{C}$, the MIC was determined by visual examination at the lowest concentration of peptide in wells with no cell growth.

\section{Antimicrobial activity of cosmetic formulation}

In order to confirm the bactericidal ability of KR-12-pa, methylparaben, and Scutellaria baicalensis extract in cosmetic formulation, Escherichia coli and Staphylococcus aureus were cultured in $5 \mathrm{~mL}$ of $\mathrm{LB}$ medium to an absorbance of 0.5 at OD600 at $37{ }^{\circ} \mathrm{C}$. Then, the culture was diluted to a concentration of $1 / 2$ with $1 \%$ peptone. Thereafter, $0,25,50,100$, and $200 \mu \mathrm{g} / \mathrm{mL}$ of each strain were mixed with the samples and incubated at $37{ }^{\circ} \mathrm{C}$ for $24 \mathrm{~h}$. Thereafter, physiological saline was added to dilute the final concentration to $1 \times 10^{7} \mathrm{CFU} / \mathrm{mL}$, and then $100 \mu \mathrm{L}$ of the mixture was inoculated in LBA plates, and cultured at $37{ }^{\circ} \mathrm{C}$ for $16 \mathrm{~h}$, and the number of cells was counted.

\section{Mammalian cell cultures}

RAW264.7 cells were cultured in Dulbecco's modified Eagle's medium (DMEM) supplemented with 10\% fetal bovine serum (FBS) and antibiotic-antimycotic solution (100 units $/ \mathrm{mL}$ penicillin, $100 \mu \mathrm{g} / \mathrm{mL}$ streptomycin, and $0.25 \mu \mathrm{g} / \mathrm{mL}$ amphotericin B) in $5 \% \mathrm{CO}_{2}$ at $37^{\circ} \mathrm{C}$. Cultures were passed every 2 to 4 days, and cells were detached by brief trypsin treatment and visualized with an inverted microscope. All cells were maintained under the aforementioned media conditions, and passages 2 to 10 were used for all cell lines.

\section{MTT assay}

Cytotoxicity of KR-12-pa and melittin peptides was determined using MTT assay against RAW264.7 cells. RAW264.7 cells were seeded on 96-well microplates at a density of $1 \times 10^{4}$ cells/well in $150 \mu \mathrm{L}$ DMEM containing $10 \%$ FBS. Plates were incubated for $24 \mathrm{~h}$ at $37^{\circ} \mathrm{C}$ in $5 \%$ $\mathrm{CO}_{2}$. The KR-12-pa peptide solution $(20 \mu \mathrm{L})$ (serial 2fold dilutions in DMEM) was added, and the plates were further incubated for $24 \mathrm{~h}$. Wells containing cells without peptides served as controls. Then, $20 \mu \mathrm{L}$ of MTT solution $(5 \mathrm{mg} / \mathrm{mL})$ was added in each well, and the plates were incubated for a further $4 \mathrm{~h}$ at $37^{\circ} \mathrm{C}$. Precipitated MTT formazan crystals were dissolved by addition of $100 \mu \mathrm{L}$ of dimethyl sulfoxide (DMSO) for $5 \mathrm{~min}$. Absorbance at $550 \mathrm{~nm}$ was measured using a microplate reader (PHOmo). Cell survival was expressed as a percentage of the ratio of $A_{550}$ of cells treated with peptide to that of cells only. The percentage inhibition was calculated as

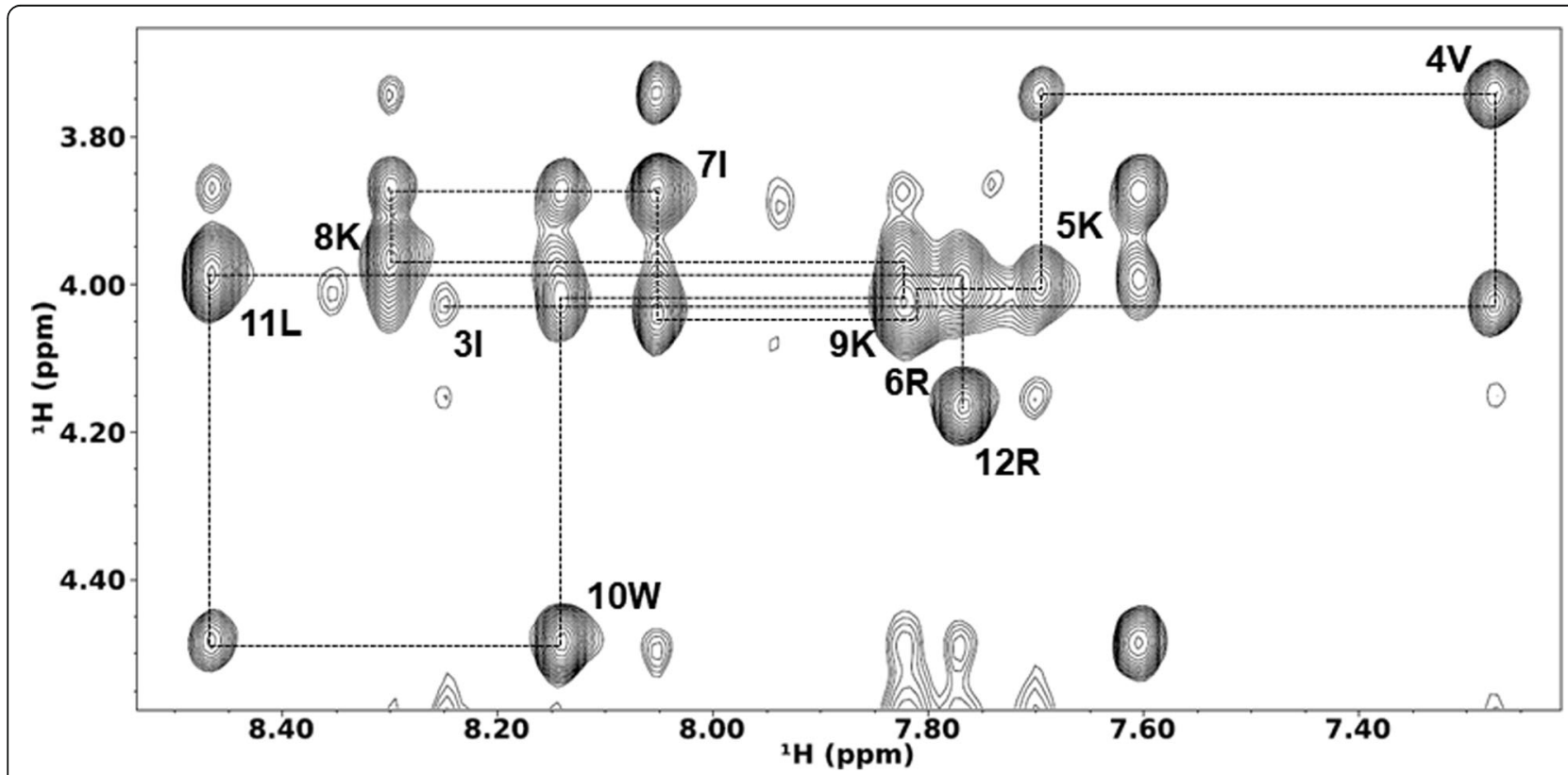

Fig. 3 Sequential $d_{a N}(i, i+1)$ Nuclear Overhauser Effect (NOE) connectivities for KR-12-pa in a ${ }^{1} \mathrm{H}$ NOESY spectrum observed with a mixing time of $300 \mathrm{~ms}$ at $298 \mathrm{~K}$. Intraresidue $\mathrm{NH}-\mathrm{C}^{\mathrm{a}} \mathrm{H}$ cross peaks are labeled with the residue number of KR-12-pa using standard single-letter amino acid abbreviations 
Table 1 Proton chemical shifts of KR-12-pa in 50\% TFE at $298 \mathrm{~K}$

\begin{tabular}{|c|c|c|c|c|}
\hline Sequence & $\mathrm{HN}$ & $\mathrm{Ha}$ & $H \beta$ & Others \\
\hline 3 lle & 8.25 & 4.04 & 1.89 & Hү2: 0.95 \\
\hline 4 Val & 7.27 & 3.75 & 2.16 & Hү1: 1.03; Hү2: 1.03 \\
\hline 5 Lys & 7.70 & 4.01 & 1.94 & Hү: 1.47, 1.60; Hס: 1.75 \\
\hline $6 \operatorname{Arg}$ & 7.81 & 4.06 & 1.94 & Hү: 1.62, 1.71; Hס: 3.12 \\
\hline 7 lle & 8.05 & 3.88 & 1.99 & Hү1: 1.16; Hү2: 1.01; Hס1: 0.85 \\
\hline 8 Lys & 8.30 & 3.97 & $1.85,1.93$ & Hү: 1.40; Hס: 1.69 \\
\hline 9 Lys & 7.83 & 4.03 & 1.94 & $\mathrm{H \gamma :}: 1.41,1.57 ; \mathrm{H} \delta: 1.71$ \\
\hline 10 Trp & 8.14 & 4.49 & $3.40,3.55$ & Hع1: 9.83; Hz2: 7.44; HH2: 7.19; Hz3: 7.10; Hع3: 7.61 \\
\hline 11 Leu & 8.47 & 4.01 & 1.89 & 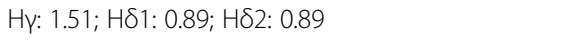 \\
\hline $12 \mathrm{Arg}$ & 7.77 & 4.18 & $1.91,1.96$ & Hү: 1.71,1.83; Hס: 3.19 \\
\hline
\end{tabular}

cell viability $(\%$ control $)=100 \times($ absorbance of treated sample)/(absorbance of control).

\section{Results and discussion}

\section{Preparation of KR-12-pa}

Human cathelicidin LL-37 is known as an attractive AMP for treatment of endotoxin shock and sepsis caused by gram-negative bacterial infection because of its effective binding and neutralization of LPS (Rosenfeld et al. 2006). However, there are many drawbacks of LL-37 as a therapeutic agent. For example, LL-37 causes significant hemolysis of human red blood cells and it is too long to be developed as a peptide drug for bacterial infection and inflammatory disease (Ciornei et al. 2005). Therefore, the short KR-12 peptide was identified as a minimized sequence from LL-37 that retained antimicrobial activity (Jacob et al. 2013). Furthermore, to enhance cell specificity and cytotoxic activity, various KR-12 analogs have been designed and synthesized. Jacob et al. suggested that the KR12-pa peptide consisting of KRIVKRIKKWLR sequence showed effective antimicrobial and anti-

Table 2 The final constraints and structural statistics for KR-12-

\begin{tabular}{ll} 
pa & \\
\hline Total number of distance restraints & 142 \\
\hline Short range $(|i-j| \leq 1)$ & 102 \\
Medium range $(1<|i-j|<5)$ & 39 \\
Long range $(|i-j| \geq 5)$ & 1 \\
CYANA target function $\left(\AA^{2}\right)$ & $0.0079 \pm 0.0029$ \\
Ramachandran plot regions (all residues) (\%) & 67.5 \\
Residues in most favored regions & 32.5 \\
Residues in allowed regions & 0 \\
Residues in disallowed regions & $0.14 \pm 0.04$ \\
RMS deviations from the mean coordination (residues 3-11) $(\AA)$ \\
Backbone heavy atoms \\
All heavy atoms
\end{tabular}

inflammatory activities without any mammalian activity (Jacob et al. 2013). In the sequence of KR-12-pa, Gln5 and Asp9 were substituted with Lys residues and Phe10 was mutated to Trp from the wild-type KR-12 sequence (Fig. 1a). These mutations induced an almost symmetric amphipathic helical structure with more positive and hydrophobic property based on the helical wheel diagram analysis (Fig. 1b, c). We synthesized the KR-12-pa peptide using SPPS with Fmoc-chemistry. The purity and molecular weight of the synthesized KR-12-pa peptide were confirmed by RP-HPLC and LC-MS analysis. The purity of the final product of KR-12-pa was above 95\%.

\section{Secondary structure of KR-12-pa}

To verify the secondary structure of KR-12-pa, we used CD spectroscopy. In the sodium phosphate buffer, the KR-12-pa peptide adopts a random coil conformation showing a negative minimum between 195 and $200 \mathrm{~nm}$ (Fig. 2). This is consistent with typical CD characteristics of linear AMP under aqueous buffer conditions. By adding 50\% TFE, an agent mimicking the hydrophobic characteristics of a microbial membrane-comparable environment, the random coil CD spectrum of KR-12-pa changed to an $\alpha$-helix $C D$ spectrum with two minima at 208 and $222 \mathrm{~nm}$ (Fig. 2). The content of $\alpha$-helix of KR12 -pa in $50 \%$ TFE was over $91 \%$, which was calculated from the CD spectrum using the Selcon3 program (Whitmore and Wallace 2008).

\section{Structure calculation of KR-12-pa}

We solved the three-dimensional structure of KR-12-pa peptide in 50\% TFE buffer condition using 2D NMR spectroscopy. The NMR structure of KR-12-pa was calculated based on distance restraints between hydrogen atoms in KR-12-pa obtained from NOE constraints from ${ }^{1} \mathrm{H} 2 \mathrm{D}$ NOESY spectrum. The ${ }^{1} \mathrm{H}$ resonance assignments were accomplished by sequential NOE assignment. The spin system of each amino acid in KR-12-ps was 
identified by 2D DQF-COSY and TOCSY spectra. The identified spin systems were ordered along the primary sequence of KR-12-pa in the HA-NH region of the 2D NOESY spectrum (Fig. 3). The sequential $d_{\alpha N}(\mathrm{i}, \mathrm{i}+1)$ NOE connectivities were indicated by dotted lines. The two residues (Lys1 and Arg2) at the $\mathrm{N}$ terminus were not detected in any spectra, probably due to exchange with water molecules. The peaks from backbone amide protons were well dispersed between 7.2 and $8.5 \mathrm{ppm}$. The assigned ${ }^{1} \mathrm{H}$ chemical shifts of the KR-12-pa are summarized in Table 1. The NMR structures of KR-12pa were calculated using the CYANA software. The final 20 structures were selected by low target function values. The final CYANA constraints and structural statistics for the KR-12-pa are shown in Table 2.

\section{NMR structure of KR-12-pa}

The 20 NMR structures of KR-12-pa were well converged except for $\mathrm{N}$-terminal residues (Fig. 4a). The root-mean-square deviation (RMSD) values were $0.14 \pm$ $0.04 \AA$ for backbone heavy atoms and $0.79 \pm 0.13$ for all heavy atoms in residues Ile3 to Leu11 (Table 2). The Nterminal residues (Lys1 and Arg2) were highly disordered, resulting from no distance constraints since the resonance from these two residues completely disappeared in all NMR spectra. The NMR structure of the KR-12-pa is composed of an $\alpha$-helix consisting of residues Ile3-Leu11 (Fig. 4b). Consistent with the predicted helical wheel diagram, the wild-type KR-12 peptide forms an incomplete amphipathic helical structure (Figs. $1 \mathrm{~b}$ and $4 \mathrm{~b}$ ). Although the hydrophobic residues in KR-12 peptide are well aligned on one face of the helical structure, the mixture of positively and negatively charged residues of KR-12 forms the other face of the helical structure of KR-12. However, the KR-12-pa peptide forms a nearly perfect amphipathic helical conformation of hydrophobic and positively charged residues (Figs. 1c and 4c). These structural properties of KR-12-pa might be responsible for the enhanced antibacterial and antiendotoxic activity compared to that of the wild-type KR-12 peptide.

\section{Antimicrobial activity of KR-12-pa and cosmetic preservatives}

The antimicrobial activities of the short KR-12-pa analog and commercial cosmetic preservatives (methylparaben and Scutellaria baicalensis extract) were tested by obtaining MIC values with three gram-negative and three gram-positive bacteria, and a C. glabrata strain. Table 3 shows the MICs of the KR-12-pa ranging from 1.6 to $3.2 \mu \mathrm{g} / \mathrm{mL}$ for gram-negative and gram-positive bacteria. The MICs of the KR-12-pa were lower than those of the well-known antimicrobial peptide, melittin, and commercial cosmetic preservatives, methylparaben, and Scutellaria baicalensis extract. In particular, the cosmetic preservatives could not inhibit the growth of bacteria even at $205 \mu \mathrm{g} / \mathrm{mL}$ concentration.

\section{Concentration-dependent antibacterial activity in cosmetic formulation}

The representative gram-negative E. coli and grampositive $S$. aureus were used to confirm the bactericidal activity of the KR-12-pa in a cosmetic formulation containing $3 \%$ of glycereth-26 as a moisturizer with $0.05 \%$ Xanthan gum. As a result, the cosmetic formulation treated with KR-12-pa killed the gram-negative E. coli at

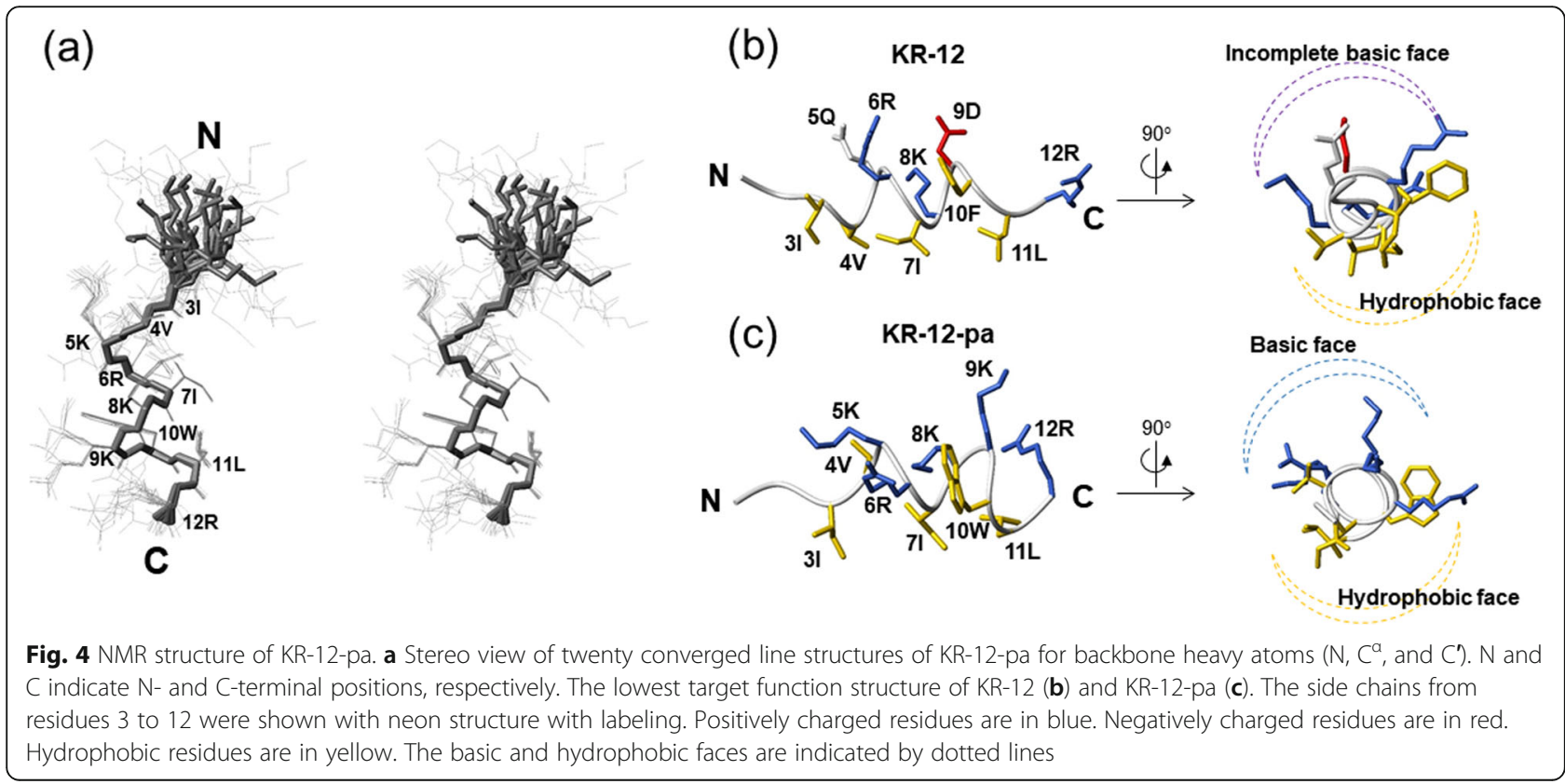


Table 3 Minimal inhibitory concentration (MIC) of KR-12-pa, methylparaben, Scutellaria baicalensis extract, and melittin

\begin{tabular}{|c|c|c|c|c|}
\hline \multirow[t]{2}{*}{ Strain } & \multicolumn{4}{|c|}{$\mathrm{MIC}(\mu \mathrm{g} / \mathrm{mL})$} \\
\hline & KR-12-pa & Methyl paraben & Scutellaria baicalensis extract & Melittin \\
\hline \multicolumn{5}{|l|}{ Gram-negative } \\
\hline Escherichia coli (KCTC 1682) & 1.6 & $>205$ & $>205$ & 5.7 \\
\hline Salmonella typhimurium (KCTC 1926) & 1.6 & $>205$ & $>205$ & 5.7 \\
\hline Pseudomonas aeruginosa (KCTC 1637) & 3.2 & $>205$ & $>205$ & 5.7 \\
\hline \multicolumn{5}{|l|}{ Gram-positive } \\
\hline Staphylococcus aureus (KCTC 1621) & 3.2 & $>205$ & $>205$ & 2.8 \\
\hline Bacillus subtilis (KCTC 3068) & 3.2 & $>205$ & $>205$ & 5.7 \\
\hline Staphylococcus epidermidis (KCTC 1917) & 3.2 & $>205$ & $>205$ & 5.7 \\
\hline \multicolumn{5}{|l|}{ Yeast } \\
\hline Candida glabrata (КСТC 7219) & 12.8 & $>205$ & $>205$ & 22.4 \\
\hline
\end{tabular}

concentrations starting from $25 \mu \mathrm{g} / \mathrm{mL}$ (Fig. 5a). However, the gram-positive $S$. aureus was killed at $100 \mu \mathrm{g} /$ $\mathrm{mL}$ of the KR-12-pa. The MIC of KR-12-pa for E. coli was 2-fold lower than that of KR-12-pa for S. aureus. These results indicated that the KR-12-pa peptide is more active against $E$. coli than $S$. aureus. Methylparaben and Scutellaria baicalensis extract could not induce any bactericidal activity up to $200 \mu \mathrm{g} / \mathrm{mL}$ concentration against both $E$. coli and $S$. aureus. These results suggest that the KR-12-pa peptide is highly applicable as a cosmetic preservative.

\section{Cytotoxicity of KR-12-pa}

To test the cytotoxicity of the KR-12-pa peptide, we used the MTT assay with RAW264.7 cells. Melittin was used as a control peptide having high antimicrobial activity and cytotoxicity. As a result, the KR-12-pa peptide showed very low cytotoxicity even at $128 \mu \mathrm{M}$; however, melittin showed nearly $100 \%$ cytotoxicity from $32 \mu \mathrm{M}$ onwards (Fig. 6).

\section{KR-12-pa as a cosmetic preservative}

Parabens are being used as a potential preservative in cosmetic formulation because of their effective antimicrobial activity. The most common parabens are methylparaben, ethylparaben, propylparaben, isopropylparaben, butylparaben, isobutylparaben, and phenylparaben. Crovetto et al. reported that methylparaben showed the least toxicity among the parabens but had a weak inhibitory effect on bacterial growth (Crovetto et al. 2017). In this study, methylparaben did not induce any antimicrobial activity, against any bacteria and yeast, up to $205 \mu \mathrm{g} / \mathrm{mL}$. These results suggest that a very high concentration of methylparaben should be used to exhibit effective preservative (a)

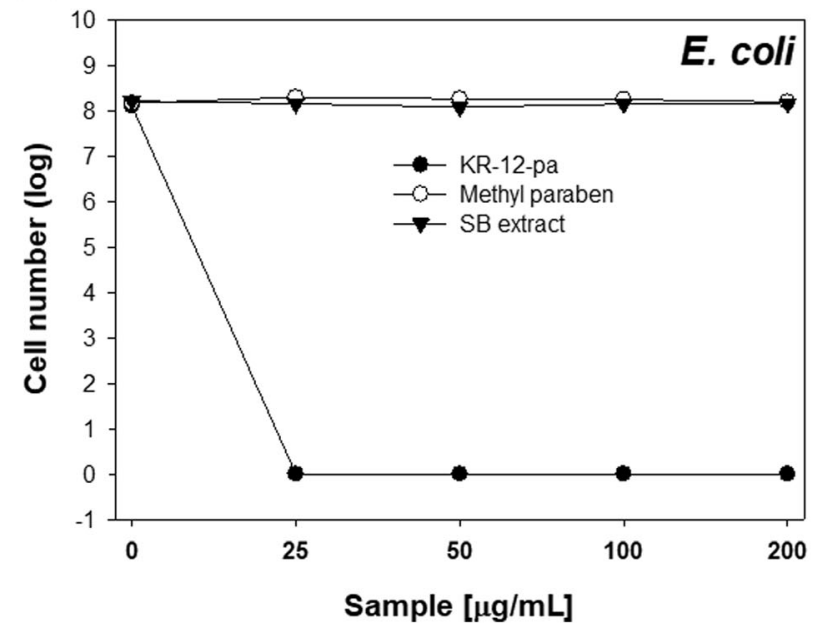

(b)

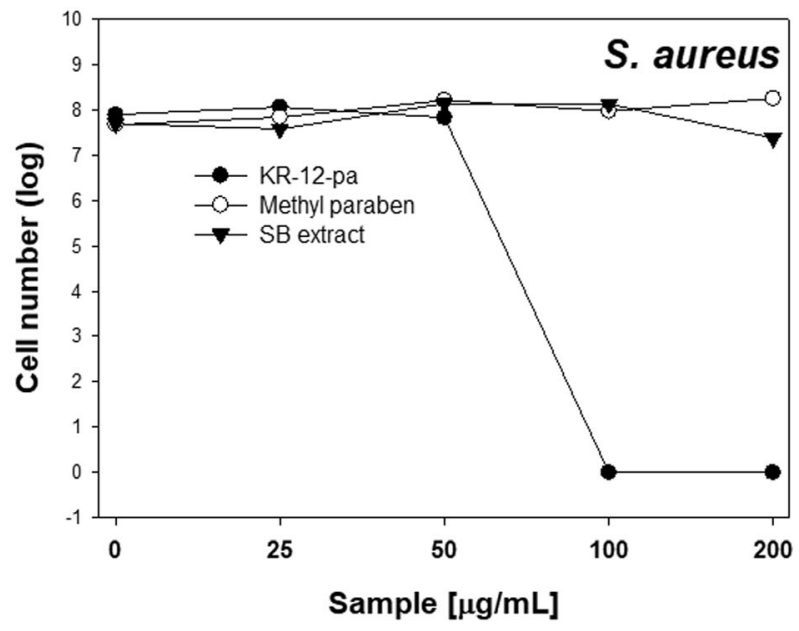

Fig. 5 Bactericidal activity of KR-12-pa, methylparaben, and Scutellaria baicalensis (SB) against gram-negative E. coli (a) and gram-positive S. aureus (b) 


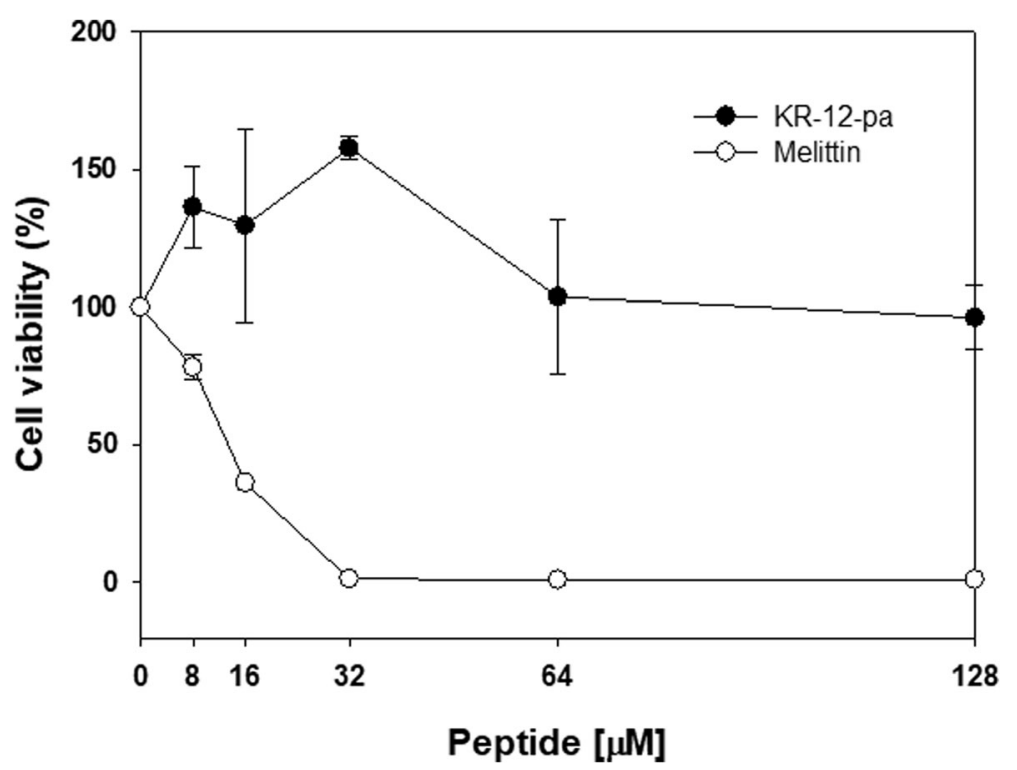

Fig. 6 Cytotoxicity by MTT assay against mouse macrophage RAW 264.7 cells induced by KR-12-pa or melittin peptides (0-512 $\mu$ M)

activity in practical usage. Scutellaria baicalensis has several biological activities, such as antioxidant, antiinflammatory, antibacterial, and antiviral activity (Huang et al. 2006; Zhao et al. 2016). Recently, the extract of Scutellaria baicalensis root has been used as an environmentally friendly cosmetic preservative. We tested the antimicrobial activity of Scutellaria baicalensis extract against six bacterial strains and a yeast. Similar to methylparaben, Scutellaria baicalensis extract did not show any growth inhibitory effect at any experimental concentration. Taken together, KR-12-pa can serve as a potential and effective preservative for cosmetic formulations.

\section{Conclusion}

With the development of cosmetics containing various functionally active substances, it is essential to secure the stability of the substances and to develop cosmetic preservatives that are harmless to the human body. AMPs are composed of peptides that are suitable for living organisms. In particular, AMPs have a broad antimicrobial activity and very little toxicity to human cells. Here, we report the three-dimensional structure and antimicrobial activity of KR-12-pa designed and optimized from human LL-37 AMP. The three-dimensional structure of KR-12-pa showed a nearly perfect amphipathic $\alpha$-helical structure. This structural characteristic may explain the enhanced biological activity of KR-12-pa over the wild-type KR-12. Moreover, KR-12-pa showed a much stronger antimicrobial activity than commercial cosmetic preservatives and maintained its antimicrobial activity within cosmetic formulations with little cytotoxicity to mammalian cells. Therefore, we suggest that KR-12-pa can be a promising cosmetic preservative.

\section{Abbreviations}

ACN: Acetonitrile; AMP: Antimicrobial peptide; CD: Circular dichroism; DMSO: Dimethyl sulfoxide; DQF-COSY: Double-quantum-filtered correlation spectroscopy; EDT: Ethanedithiol; FBS: Fetal bovine serum; FITC: Fluorescein isothiocyanate; KCTC: Korean Collection for Type Cultures; LB: Luria-Bertani; LPS: Lipopolysaccharide; MIC: Minimal inhibitory concentration; MTT: 3-(4,5Dimethylthiazol-2-yl)-2,5-diphenyltetrazolium bromide; NMR: Nuclear magnetic resonance; NOESY: Nuclear Overhauser Effect Spectroscopy; RMSD: Root-mean-square deviation; RP-HPLC: Reverse-phase highperformance liquid chromatography; SPPS: Solid-phase peptide synthesis; TFA: Trifluoroacetic acid

\section{Acknowledgements}

This work was supported by the Basic Science Research Program through the National Research Foundation of Korea (NRF) funded by the Ministry of Education, Science, and Technology of Korea (NRF-2018R1D1A1B07043540 to C.W.L) and (NRF-2018R1C1B5085101 to H.J.M).

\section{Authors' contributions}

$H Y, H J M$, and CWL conducted the experiments. JIK, HJM, and CWL designed the experiments. HY, HJM, and CWL wrote the manuscript. The authors read and approved the final manuscript.

\section{Funding}

The funding sponsors had no role in the design of the study, collection, analyses, interpretation of the data, writing of the manuscript, or the decision to publish the results.

\section{Availability of data and materials}

Research data have been provided in the article, and for more details, they are available from the corresponding author on reasonable request.

\section{Competing interests}

The authors declare that they have no competing interests.

Received: 14 January 2020 Accepted: 13 April 2020

Published online: 14 May 2020

\section{References}

Ahn HS, Nah WH, Lee JE, Oh YS, Gye MC. Toxicity and endocrine disrupting effect of parabens. Korean J Environ Biol. 2009;27:323-33. 
Bax A, Davis DG. MLEV-17-based two-dimensional homonuclear magnetization transfer spectroscopy. J Magn Reson 1985;65:355-360. https://doi.org/10. 1016/0022-2364(85)90018-6.

Cho IJ, Kim MS, Kim HP, Kang SM. Antimicrobial effects of omija (Schizandra chinensis) flesh and seed extracts against human skin pathogens. J Korean Soc Cosmet. 2015;21:545-53.

Choun YM, Jung JY, Ko KS. A study on the possibility of functional cosmetic material by antioxidant and antimicrobial activity of Chelionium majus extract. J Korean Soc Cosmet. 2017;23:921-9.

Ciornei CD, Sigurdardottir T, Schmidtchen A, Bodelsson M. Antimicrobial and chemoattractant activity, lipopolysaccharide neutralization, cytotoxicity, and inhibition by serum of analogs of human cathelicidin LL-37. Antimicrob Agents Chemother. 2005;49:2845-50 https://doi.org/10.1128/AAC.49.7.28452850.2005 .

Crovetto SI, Moreno E, Dib AL, Espigares M, Espigares E. Bacterial toxicity testing and antibacterial activity of parabens. Toxicol Environ Chem. 2017;99:858-68 https://doi.org/10.1080/02772248.2017.1300905.

Delaglio F, Grzesiek S, Vuister GW, Zhu G, Pfeifer J, Bax A. NMRPipe: a multidimensional spectral processing system based on UNIX pipes. J Biomol NMR. 1995;6:277-93 https://doi.org/10.1007/bf00197809.

Herrmann T, Güntert P, Wüthrich K. Protein NMR structure determination with automated NOE assignment using the new software CANDID and the torsion angle dynamics algorithm DYANA. J Mol Biol. 2002;319:209-27 https://doi.org/10.1016/S0022-2836(02)00241-3.

Hoskin DW, Ramamoorthy A. Studies on anticancer activities of antimicrobial peptides. Biochim Biophys Acta. 2008;1778:357-75 https://doi.org/10.1016/j. bbamem.2007.11.008.

Huang W-H, Lee A-R, Yang C-H. Antioxidative and anti-inflammatory activities of polyhydroxyflavonoids of Scutellaria baicalensis GEORGI. Biosci Biotechnol Biochem. 2006;70:2371-80 https://doi.org/10.1271/bbb.50698.

Hwang SH, Park C-H. Preservation of cosmetics by ethanol extract of Scutellaria baicalensis GEORGE. Korean Soc Biotechnol Bioeng. 2009;24:347-52.

Jacob B, Park IS, Bang JK, Shin SY. Short KR-12 analogs designed from human cathelicidin LL-37 possessing both antimicrobial and antiendotoxic activities without mammalian cell toxicity. J Pept Sci. 2013;19:700-7 https://doi.org/10. 1002/psc.2552.

Johansson J, Gudmundsson GH, Rottenberg ME, Berndt KD, Agerberth B. Conformation-dependent antibacterial activity of the naturally occurring human peptide LL-37. J Biol Chem. 1998;273:3718-24 https://doi.org/10. 1074/jbc.273.6.3718.

Johnson BA, Blevins RA. NMR view: a computer program for the visualization and analysis of NMR data. J Biomol NMR. 1994;4:603-14 https://doi.org/10.1007/ bf00404272.

Kang X, Elson C, Penfield J, Kirui A, Chen A, Zhang L, Wang T. Integrated solidstate NMR and molecular dynamics modeling determines membrane insertion of human $\beta$-defensin analog. Commun Biol. 2019;2:402 https://doi. org/10.1038/s42003-019-0653-6.

Kim J-D. The new technology development strategy of cosmeceuticals with use advanced materials resources. J Soc Cosmet Scientists Korea. 2004;30:427-38.

Koradi R, Billeter M, Wüthrich K. MOLMOL: a program for display and analysis of macromolecular structures. J Mol Graph 1996;14:51-55. https://doi.org/10. 1016/0263-7855(96)00009-4.

Kwon MJ, Moon JS, Choi EY. Development of preservatives for cosmetics using herbal extracts. J Korean Soc Cosmet. 2015;21:347-56.

Mani R, Cady SD, Tang M, Waring AJ, Lehrer RI, Hong M. Membrane-dependent oligomeric structure and pore formation of a $\beta$-hairpin antimicrobial peptide in lipid bilayers from solid-state NMR. Proc Natl Acad Sci U S A. 2006;103: 16242 https://doi.org/10.1073/pnas.0605079103.

Novak A, Sydney E, Soccol C. Biocosmetics. Biotransformation of waste biomass into high value biochemicals. 2014;:389-411. https://doi.org/10.1007/978-14614-8005-1_16.

Porcelli F, Ramamoorthy A, Barany G, Veglia G. On the role of NMR spectroscopy for characterization of antimicrobial peptides. Methods Mol Biol. 2013;1063: 159-80 https://doi.org/10.1007/978-1-62703-583-5_9.

Rosenfeld Y, Papo N, Shai Y. Endotoxin (lipopolysaccharide) neutralization by innate immunity host-defense peptides. Peptide properties and plausible modes of action. J Biol Chem. 2006;281:1636-43 https://doi.org/10.1074/jbc. M504327200.

Vandamme E. Biocosmetics produced via microbial and enzymatic synthesis. Agro Food Ind Hi Tec. 2001;12:11-8 http://hdl.handle.net/1854/LU-147499.
Whitmore L, Wallace BA. Protein secondary structure analyses from circular dichroism spectroscopy: methods and reference databases. Biopolymers. 2008;89:392-400 https://doi.org/10.1002/bip.20853.

Zhao Q, Chen XY, Martin C. Scutellaria baicalensis, the golden herb from the garden of Chinese medicinal plants. Sci Bull (Beijing). 2016;61:1391-8 https:// doi.org/10.1007/s11434-016-1136-5.

\section{Publisher's Note}

Springer Nature remains neutral with regard to jurisdictional claims in published maps and institutional affiliations.

\section{Submit your manuscript to a SpringerOpen ${ }^{\circ}$ journal and benefit from:}

- Convenient online submission

- Rigorous peer review

- Open access: articles freely available online

- High visibility within the field

- Retaining the copyright to your article

Submit your next manuscript at $\boldsymbol{\nabla}$ springeropen.com 